\title{
GLOBALIZACIÓN Y LITERATURAS HISPÁNICAS: DE LO POSNACIONAL A LA NOVELA GLOCAL
}

\author{
Vicente LUIS Mora \\ Investigador y escritor \\ -No se puede estar toda la vida en el mismo sitio. \\ -¿Por qué no? \\ -Porque ya no eres la misma persona. \\ Belén Gopegui, Acceso no autorizado
}

INTRODUCCIÓN

En su novela Rockabilly (2011), el narrador argentino-estadounidense afincado en Chile Mike Wilson describe cómo uno de sus personajes, Suicide Girl, provoca un incendio en su casa materna. En El niño que robó el caballo de Atila (2013), del español Iván Repila, el chico protagonista, que ha sido tirado a un pozo por su madre, logra escapar y vuelve a la casa familiar para matarla. En Intemperie (2013), de Jesús Carrasco, otro niño protagonista huye del hogar y elige el hambre y cualquier castigo antes que regresar a él. Las escenas pueden ser vistas como gestos narrativos extremos o como parábola de algo que está ocurriendo en la narrativa última en español, ya sea en América del Norte, en España o en América del Sur: Ios narradores, nietzscheanamente (Molinuevo 2004: 24-25), ya no desean como Ulises regresar a la casa paterna, sino verla arder (como Jenofonte vio el lar paterno quemado por un rayo en la Anábasis), destruir el hogar, devastar el origen. Bernat Castany Prado recuerda cómo en El frío Thomas Bernhard describe que su padre quemó la casa de sus progenitores, y "con ese espectáculo de la casa de sus padres ardiendo no solo había extinguido en él su patria sino, en general, el concepto de patria" (2012: 17).

Julio Ortega ha expuesto en alguna ocasión que la narrativa española joven más interesante se caracteriza por ser una narrativa española sin España. En la misma dirección, pero en términos geográficos más amplios y en un trabajo 
titulado significativamente "Narrar sin fronteras", la profesora Francisca Noguerol ha escrito que al reflexionar sobre la producción narrativa latinoamericana de los últimos años, "si existe un término que pueda definirla, este es el de la extraterritorialidad" (2008: 20); Ángel Esteban y Jesús Montoya se inclinan por el concepto "multiterritorialidad" (2009: 9). Los códigos geográficos tradicionales parecen haber sido vencidos, o estar en proceso de serlo, por una concepción narrativa glocal (local y global a la vez; el término fue introducido en 1995 por R. Robertson; Rodríguez Ibáñez 2012: 122, Borja y Castells 1997), tendente a buscar y a buscarse en espejos diferentes, plurinacionales, que incluyen también lecturas e influencias de otras lenguas y países ${ }^{1}$, como después veremos. Y si esto es así en la literatura tradicional, el fenómeno es todavía más visible en la literatura digital, que traspasa por naturaleza cualquier concepto secular de nacionalidad; así, Dolores Romero López ha podido hablar, con ecos derrideanos, de "disemiNación" (2008: 219).

\section{LA GLOBALIZACIÓN COMO MARCO SOCIOPOLÍTICO}

No es este el lugar para ahondar en qué sea la globalización, pero si queremos explorar sus consecuencias literarias debiéramos al menos establecer una descripción sintética.

Uno de los primeros problemas con que se encuentra cualquier aproximación a los efectos de la globalización es delimitar qué se entiende por tal, por cuanto aquellos serán diferentes según el contorno que demos al concepto. Las diferentes concepciones (hasta catorce clasificaciones establecen José B. Terceiro y Gustavo Matías en Digitalismo) van desde considerar que la globalización consiste solo en la mundialización de las transacciones financieras hasta considerarla una nueva cosmovisión, del mismo modo que el liberalismo, por ejemplo, lo fuera para otras épocas históricas.

A lo mejor una definición requiere, como el mismo concepto, un análisis de los agentes que lo han hecho posible. Languetin establecía (1988) principalmente tres factores que habrían facilitado el rápido crecimiento del proceso globalizador:

1) El desarrollo de la informática y las telecomunicaciones, que, reduciendo espectacularmente los costes, posibilitaron la internacionalización de los mercados y la instrumentación de complicadas operaciones tales como los futuros, las opciones, o los swaps. Andreu y Arasa confirmaban este dato con la observación de Angermueller, por la cual ya en 1988 el coste del envío de información se había reducido, gracias a las nuevas tecnologías, hasta en un 95\%. Finalmente la globalización, que avanzaría a pasos agigantados en la segunda mitad del siglo

\footnotetext{
${ }^{1}$ Esta es la tesis defendida por Jorge Carrión: "Ian Jack se despedía del escritor John McGahern, que acababa de morir en su granja de County Leitrim, Irlanda, y reflexionaba sobre el hecho de que cada vez son menos los artistas cuya obra depende del conocimiento de la gente y de paisaje donde nació, vivió y murió. Efectivamente, el artista global se impone, en conflicto directo con el artista globalizado" (2009: 29). El mismo autor, al terminar su novela Los muertos, fecha y localiza los lugares en los que ha redactado el texto: "Jordania/Perú/ Francia/España" (2010: 144).
} 
$\mathrm{xx}$, coincidiendo con la aparición de las primeras formas de toyotismo descentralizador de los procesos productivos, vino de la mano de los aeropuertos, las autopistas y, sobre todo, la emergencia de las tecnologías de la información que facilitaban el control descentralizador (Terceiro y Matías 2002: 75).

2) Las políticas de liberalización y desregulación, tales como el levantamiento del contrato de cambios por parte de varios países, o la abolición de los reglamentos sobre los tipos de interés máximo.

3) La volatilidad incrementada de los nuevos tipos de interés, que ha motivado el estudio de nuevos instrumentos innovadores para operar con ventaja en ese mercado.

Terceiro y Matías ven como notas de la globalización la novedad relativa, la multidimensionalidad, complejidad y heterogeneidad de su núcleo estructural, y la dependencia de la universalización de la información a través de sus tecnologías (2002: 139). Kevin Kelly ha señalado como notas esenciales de la nueva economía el pico demográfico, la aceleración tecnológica, la revolución financiera y la apertura global. A estos elementos habría que añadir otros, como los desequilibrios financieros internacionales, el papel del Fondo Monetario Internacional y del Banco Mundial, la política de desarrollo de las multinacionales, y la receta política de la economía de mercado unida al sistema democrático neoliberal, vendida como natural (según el Slavoj Žižek de El frágil absoluto). A escala macroeconómica, Armand Mattelart hace ver que, siguiendo las tesis de Theodor Levitt, se ha conseguido vender la globalización como el colmo del estado del bienestar, la forma más rápida de que los pueblos menos desarrollados accedan a una estabilidad económica y a la filosofía de los servicios públicos, produciéndose, como ha denunciado Samir Amin en El capitalismo en la era de la globalización, una manipuladora identificación entre expansión capitalista y desarrollo, que se basaba en la incumplida promesa de que los beneficiarios sostendrían a los perjudicados (Estefanía 1997: 252). No hay que decir que las observaciones a favor o en contra de la economía globalizada están a su favor en proporción directa a la proximidad al mercado; quizá por eso Grady Means y David Schenider no veían en Metacapitalism (2000) ningún defecto a la nueva economía. Esta globalización, como ya sabemos, también se caracteriza por la integración mundial a impulsos de las técnicas de comunicación, y por una desregulación acrecentada (Philippe Quéau, Mochón), analizada a conciencia en el conocido documental Inside Job (2010, Charles Ferguson).

No hay consenso respecto a su momento de comienzo. Para Serge Gruzinski, la globalización tiene cinco siglos de antigüedad, aunque la confunde indebidamente con expansión territorial. Ulrich Beck recopila varias tesis sobre el nacimiento de la misma: Marx y Engels ya hablaban de ella en 1848; Inmanuel Wallerstein también sitúa su principio en el siglo xv, Robertson en 1870-1920, Anthony Giddens en el siglo xVIII, y Perlmutter con ocasión de la caída del Muro de Berlín y el derrumbe de la economía socialista (hecho que supuso un cambio cualitativo en la implantación del proceso). Néstor García Canclini (2005: 45-46) sostiene que las explicaciones que buscan más lejanamente en el tiempo el origen de la globalización se amparan en factores fundamentalmente económicos, 
mientras que las que lo cifran en momentos más próximos consideran las demás manifestaciones del fenómeno. En cualquier caso, y tras mostrar con datos cómo el mundo actual es más injusto, más desigual, con más pobreza y esclavitud, el historiador Josep Fontana culmina su monumental Por el bien del imperio. Una historia del mundo desde 1945 (2011) con este significativo párrafo:

... este es el mundo que ha creado el capitalismo realmente existente, una vez ha conseguido librarse de la amenaza del socialismo realmente existente y, a la vez, de las fuerzas que se le resistían en el interior de su propia sociedad, a las que ha conseguido controlar hasta hacerlas inofensivas. Pero en la hora misma de esta victoria parecen surgir unas nuevas contestaciones, incipientes y poco organizadas por el momento, que representan una inesperada amenaza al poder de la "jerarquía global existente". (Fontana 2011: 974)

La primavera árabe, los indignados europeos y otras formas de malestar se oponen como un espejo contestatario a los excesos de la globalización, aunque en lo literario veremos cómo también se han producido algunas respuestas.

\section{De la economía a la cultura. Lo posnacional como marbete crítico}

Como es natural, la globalización también tiene efectos culturales, uno de los cuales es la homogeneización cultural, apuntada por el filósofo Félix Duque:

... lo terrible del caso es que todo ello se haya regido por una lógica perversa, según la cual todos esos problemas solo podrían ser superados mediante la aplicación masiva del mismo tipo de pensamiento, de ciencia y de tecnología (a la base: de la misma posición metafísica) que los ha engendrado, en un ejemplo de cínica circularidad perfecta. Ese tipo de circularidad indiferente, [...] engendra paradójicamente [...] en los desgraciados que sufren sus consecuencias a nivel mundial, una inextinguible ansia de homogeneización cultural. (Duque 2006: 20)

Por todos son conocidos los presumibles - no hay tiempo ahora de discriminar, disentir ni profundizar- elementos de esa homogeneización: sociedad hollywoodiense del espectáculo, consideración del inglés como lingua franca, consumismo, régimen de cultura superficial y de narrativa centrada en el melodrama o el storytelling inocuo, etc. Lo cierto es que la certidumbre de esa homogeneidad se ha asentado de tal manera que ha acabado siendo homogénea en sí misma, sin que podamos casi llegar a saber si el asentamiento del mito respondía, o no, a una realidad tangible.

En todo caso, queda por saber si, junto a una presumible cultura globalizada, consumista y vacua, habría una cultura global, digna de tal nombre, que ha encontrado un modo de utilizar las ventajas de la globalización pero sin caer en sus defectos. Un posible modo de evitarlos sería aprovechar las posibilidades de Internet o de los medios de comunicación de masas para criticar la propia globalización (García Rodríguez 2012: 304), como ha visto Paulo Kortazar en la novela del narrador Kirmen Uribe, Bilbao-New York-Bilbao (2010), globalizada hasta en 
el título, pero que a la vez contiene la semilla de la crítica en su interior: "la novela Bilbao-New York-Bilbao sirve como ejemplo de cómo se ha desarrollado la cultura postmoderna en el País Vasco. Muestra la tensión entre la asimilación de una cultura global y la resistencia que una comunidad pequeña como es la vascohablante ofrece por miedo a perder la identidad colectiva" (2012: 68). Otros autores, como luego veremos, han criticado la tiranía de los medios de comunicación de masas y su construcción de un simulacro social. Nuestra opinión es que, al menos en literatura, se han llegado a establecer las bases de una cultura de calidad que tiene unos caracteres mundializados, que pasamos a exponer.

El primero de ellos, precisamente por global, sería el de la superación de lo nacional como categoría territorial privilegiada, que ha operado sin reservas desde el siglo xIx (lanes 2006: 391). Da la impresión de que lo posnacional es ya una categoría propia dentro de los estudios literarios últimos, sobre todo hispanoamericanos. Gonzalo Navajas exponía no hace mucho que "de la nación como foco central referencial de toda la empresa cultural nos hemos trasladado progresivamente a una situación posnacional en la que la nación es un componente esencial pero no único en la creación y la comprensión e interpretación" (2012: 158). Bernat Castany Prado, en su temprano ensayo Literatura posnacional (2007) apunta algunas cuestiones que nos parecen del mayor interés. La primera es que "no podemos considerar en términos absolutos sino relativos que la literatura posnacional es diferente de la nacional. Ciertamente, son muchos los elementos comunes que ambas esferas literarias presentan" (2007: 175); la segunda es que "el componente nacional [...] no ha desaparecido, sino que se está redefiniendo" (167). En tercer lugar hay que entender que ambos tipos no son opuestos: "El concepto de heterogeneidad puede ayudarnos a no caer en la tentación de distinguir dos tipos de literatura, nacional y posnacional, sino también a entender ambas tendencias como los polos de una relación dialéctica y compleja que se da dentro de cada cultura, autor y obra" (186).

Esta complejidad y esta dialéctica se ven a la perfección en la lectura que hace Jorge Carrión de Dolerse. Textos desde un país herido, de la mexicana Cristina Rivera Garza:

... la literatura no tiene por qué ser nacional. Si hemos superado la circunscripción de un autor a su estado-nación, si nos sentimos nómadas estéticos, artistas cosmopolitas, seres radicantes, lectores internacionales: ¿cómo nos va a doler nuestro país? Hay pocas expresiones que sienta yo tan ajenas como el "Me duele España" de Unamuno. Y sin embargo ahí está Dolerse. Textos desde un país herido. (Carrión 2013: 25)

En su ensayo Mentiras contagiosas, el mexicano Jorge Volpi defiende su derecho a insertarse en otras tradiciones: "quizás la nacionalidad de un autor revele claves sobre su obra, pero ello no indica -o al menos no tiene por qué indicar- que esté fatalmente condenado a hablar de su entorno, de los problemas y referentes de su localidad, o incluso de sí mismo. La ficción literaria no conoce fronteras: si ello es visto como un triunfo de la globalización y del mercado es porque no se comprende la naturaleza abierta de la literatura" (2008: 183), ideas 
que luego amplió en El insomnio de Bolívar (2009). Volpi apunta el centro conceptual del asunto, pero es plausible entender asimismo que la globalización económica y la revolución informacional han ensanchado aún más la natural libertad geográfica de la cultura en general y de la literatura como caso específico, como luego desarrollaremos. Alexandra Saum-Pascual, estudiando en su tesis doctoral a varios narradores españoles de las últimas promociones, explica:

... como trataremos de demostrar, las obras "nuevas" a tratar aquí, en vez de convertirse en meras reproducciones de la propaganda extranjera, son capaces de cuestionar su función -y la función propia del arte tradicional en una época digital- a través de un muy controlado uso de la estética que las imbuye, facilita e, irónicamente, problematiza. La temática subyacente, y en muchos casos muy a su pesar, mantiene una relación traumática y paradójica con las consecuencias de la globalización tecnológica que les da origen y sentido, por un lado, y amenaza con eliminar este sentido identitario particular, por otro. (Saum-Pascual 2012: 35)

Se han apuntado otros modos de escapar de lo nacional en la literatura hispanoamericana: el frecuente recurso a la distopía y la novela postapocalíptica, que se sitúa imaginariamente en un futuro post-civilizatorio, fuera ya de lo territorial, y también la sátira humorística (Aníbal González²). Pero hay más.

La profesora Jean Franco recogía en su trabajo "Narrativas de la globalización" la opinión postautónoma de Josefina Ludmer, sobre la que luego volveremos, para quien la literatura latinoamericana "ya no es manifestación de identidad nacional y territorial. Se trata de una forma de territorialización que es el sitio y escenario de otras subjetividades o identidades y otras políticas" (citada en Franco 2008: 20). Franco, que estudia en su texto las novelas 2666, de Roberto Bolaño, y Mano de obra, de Diamela Eltit, señala el mercado del consumo y la alienación laboral de la segunda novela y la impune frontera mexicana de la primera, como lugares donde los imaginarios globalizados se convierten en "imaginarios apocalípticos" (2008: 22). Puede parecer obvio que la narrativa hispánica, entendiendo por tal la suma de las letras latinoamericanas, españolas y chicanas en castellano, ha ampliado su modo geográfico y cultural de expresarse, pero habría que ahondar en las preguntas cómo y por qué.

\section{3. ¿Se puede escapar de lo nacional?}

La realidad posnacional no ha eliminado la dialéctica con la nacional, como no podría ser de otro modo, teniendo en cuenta que el mismo término forma parte de lo posnacional. Del mismo modo que el sujeto posmoderno, como he-

\footnotetext{
${ }^{2}$ Aníbal González sostiene que: "Además de la crítica de la infancia y del énfasis en el presente histórico, otro recurso ya muy consagrado para combatir la nostalgia nacional lo es también el humorismo satírico"; del que pone ejemplos de Carmen Boullosa, Antonio José Ponte y Santiago Roncagliolo (2012: 93-94). Véase en el mismo número la reflexión de la propia Boullosa, "Más acá de la nación" (2012: 55-72). La crítica de la infancia y la atención al presente histórico, a mi juicio, serán en la mayoría de los casos elementos de acercamiento a la realidad nacional y no de huida o superación de la misma.
} 
mos visto en La literatura egódica (2013), se configura de modo muy específicamente por la tensión inherente (Žižek) respecto al sujeto monádico tradicional o cartesiano, la literatura posnacional implica, en cierta forma, una consciente tensión hacia la idea de lo nacional, que se niega (aunque sea por oposición) a desaparecer. Y así se deja sentir en numerosas opiniones, como las de Montoya y Esteban: "a nuestro juicio, incluso en ciertos casos extremos en que las obras literarias tematizan la irrisión de lo nacional, estas no hacen otra cosa que hablarnos de la identidad o de cómo la identidad se reformula. Los diferentes modos de disolverse en lo global, también, se vuelven interesantes de leer" (2011:10). Navajas, en el artículo antes citado, sintetiza: "no es que la referencia local no sea ya necesaria. Por el contrario, continúa siendo un componente determinante de los hechos culturales. Lo que ocurre es que no es ya la única, ni siquiera la primaria" (2012: 157). Son opiniones generales sobre literatura hispánica, pero si descendemos a las literaturas nacionales en concreto, el argumento suele ser el mismo:

... creo que la respuesta a ¿es posnacional la literatura argentina? debería ser, aunque más no sea provisoriamente, sí. Lo que se observa, más allá de las diferentes poéticas de los autores o los distintos géneros, es que, de acuerdo a la definición de Castany o Beck, se trata de una tensión sin resolución, en la que "lo nacional", confrontado a lo cosmopolita, debe reconfigurar sus límites y sus premisas, aunque se siga escribiendo, en cada caso, desde un lugar situado. Es visible como las obras critican la nación y abjuran de una identidad esencialista, pero sin embargo, no abandonan una relación con Argentina que, aunque extrañada o indefinible, persiste como sustrato existencial. (Mandolessi 2011: 68)

Para el mexicano Pablo Raphael, "lo nacional no desaparece sino que se transforma. [...] La literatura cosmopolita piensa localmente. Una literatura sin naciones sería aburrida, y además imposible, pues no importa cuánto cambien las fronteras, el escritor siempre es hijo de una situación concreta" (2011: 257). Se admite, por tanto, un cierto cambio en la cosmovisión, pero no es un cambio integral, ya que para estas opiniones el residuo de lo nacional queda aún demasiado anclado en el imaginario. Quizá sería más preciso hablar de lo posnacional como una tendencia, un deseo o una dirección, más que un hecho irrevocable y tajante. Pero es una tendencia muy fuerte. Vamos a intentar esclarecer algunos de los factores que pueden haber provocado su aparición.

\section{LA DESFIGURACIÓN DE LA FIGURA DEL ESCRITOR ANTES CONOCIDO COMO NACIONAL}

Señaló que la opresión de saberse perdido en una urbe hasta cierto punto desconocida fue motivo suficiente para escogerla como su lugar de vida eterna. [...] Para creer que era un habitante pero también un explorador.

Mario Bellatin (2001: 31-32)

El narrador latinoamericano y el narrador español actuales de menos de cuarenta y cinco años tienen algo en común: en los mejores casos, y con muy 
pocas excepciones, son personas que se mueven. Decir que se mueven no significa que viajen como turistas (algo que hace cada vez más la generalidad de las personas, al haberse desarrollado y mejorado los medios de transporte e infraestructuras respecto a hace cincuenta años); decir que los narradores en castellano de ambos lados del charco se mueven hace referencia a que pasan largas temporadas -a veces de meses, a veces de bastantes años- fuera de su país. Pondremos unos breves ejemplos: los peruanos Doménico Chiappe, Sergio Galarza, Martín Rodríguez Gaona y Fernando Iwasaki viven en España, Peter Elmore en Estados Unidos, y la limeña Claudia Ulloa en Noruega. Para Catalina Quesada Gómez, que Julio Olaciregui se reconozca a sí mismo como postcolombiano no es otra cosa que "la rappresentazione del passaggio dall'ordine nazionale all'ordine postnazionale, dove gli estremi (globale/locale) non convergono nella sintesi nazionale" (2011: 34); por su parte, Iván de la Nuez describe el proceso en el que llega a ser "postcubano" (2010: 13), proceso que podrían reconocer también Zoe Valdés, José Antonio Ponte o el mismo Cabrera Infante hasta su fallecimiento. Los mexicanos Palou, Nettel, Curiel Rivera, Volpi, Ortuño, Corroto, Ortiz, Raphael y Padilla han residido años o lustros en España, Francia o Inglaterra. Cristina Rivera Garza enseña clases de escritura creativa en inglés en una universidad de Estados Unidos, país donde reside y escribe el boliviano Paz Soldán desde 1995. El guatemalteco Eduardo Halfon estudió también en Estados Unidos, donde han pasado la mayor parte de su vida el chileno Alberto Fuguet y algunas décadas Óscar Hahn y Lina Meruane ${ }^{3}$. Halfon se presenta a sí mismo como heredero de una tradición guatemalteca de expatriados:

\begin{abstract}
Augusto Monterroso fabuló su Guatemala desde la colonia Cuauhtémoc, en México. Mucha de la obra de Luis Cardoza y Aragón, de su poesía y sus espléndidas reflexiones sobre Guatemala, fue escrita en el exilio mexicano, en Coyoacán, donde vivió y falleció y fue sepultado. [...] Rodrigo Rey Rosa siempre será el guatemalteco en Tánger. Dante Liano aún narra sobre Guatemala en su hogar en Milán, Italia, donde vive y trabaja desde los años setenta. Francisco Goldman escribe sobre la política guatemalteca desde la distancia, incluso desde otra lengua, en su buhardilla de Brooklyn. (Halfon 2011: 24)
\end{abstract}

La chilena Claudia Apablaza escribe en su Diario de las especies: "recuerda que el tema de las fronteras materiales es algo que ya he superado" (2010: 27). El ecuatoriano Leonardo Valencia reside en Barcelona, auténtico santuario de escritores latinoamericanos desde el boom de los años sesenta y setenta del siglo pasado. Los venezolanos Juan Carlos Méndez Guédez y Juan Carlos Chi-

\footnotetext{
3 Es interesante conocer la opinión de la autora chilena Lina Meruane: "¿Esquizofrenia viajera? De vuelta en Manhattan como si nunca me hubiera ido. Algo de mí se quedó sin embargo en Berlín y no logra regresar (sigo vagando por sus calles, sigo clavada al paisaje que me acompañó desde el escritorio mientras escribía mi novela). Otro pedazo mío vive afantasmado en Santiago de Chile y se actualiza en cada visita. Y hay trozos de mi cabeza salpicados por Madrid, por Buenos Aires y el DF...; estado de Facebook de Lina Meruane, 07/01/2011. En su novela Sangre en el ojo (2012), parcialmente autoficcional, escribe: "así solía contar yo a los siete años en el colegio de mi regreso a Chile. En New Jersey yo me había olvidado del castellano. Después, en Santiago, me olvidé del inglés" (2012: 57).
} 
rinos viven y escriben en Madrid, y su compatriota Gustavo Guerrero hace lo propio en París. Bellatin ha vivido entre Perú y México, y Ricardo Piglia ha enseñado en Princeton. Otros escritores argentinos han vivido en la capital del Sena, como Gonzalo Garcés, o en España, como los narradores Rodrigo Fresán, Patricio Pron, Flavia Company o Andrés Neuman o los poetas Mariano Peyrou y Edgardo Dobry. Algo parecido sucede con los autores centroamericanos. Hablando de los escritores caribeños que selecciona para la antología Pequeñas resistencias, 4, escribe Ronaldo Menéndez:

... cuando no emigrantes confesos y practicantes, los autores del Caribe aquí reunidos demuestran cierta propensión a la ingravidez geográfica, a juzgar por sus biografías y por lo desperdigados que andan entre Estados Unidos, España y sus países exóticos. Ello me lleva a una segunda observación: no hay en sus textos nada que haga pensar que les gusta eso que llaman "identidad nacional". Los temas son marcadamente individualistas, pero también regionales. Universales y a veces vernáculos. Cínicos y a veces nostálgicos por la tierra. (Menéndez 2005: 26)

O, como ha escrito Cristina Rivera Garza,

... habría que pensar en Bolaño no como una excepción exótica (y concéntrica), claro, sino como uno entre la saga de escritores que andan por ahí, pasando por sitios y lenguas de Latinoamérica de manera esporádica, desarrollando, mientras tanto, en el mismo trance de pasar por ahí, una relación de dinámica resistencia más que de agradable acomodo con ese cúmulo de cosas a las que por falta de mejor término acabamos nombrando no pocas veces como "el entorno". ¿Hay, de verdad, un hilo que va de esos veinticuatro años que Witold Gombrowicz pasó en Argentina a, por ejemplo, Lina Meruane, esa escritora chilena que vive y produce una obra en español en el Nueva York de nuestros días? ¿Existe un hilo, se entiende que estético, entre los libros de Horacio Castellanos Moya, el centroamericano que pasa temporadas bastante largas tanto en Estados Unidos como en Europa y, digamos, Eunice Odio, la poeta costarricense que murió en México? ¿Son Unidades de Dispersión de cepa tan distinta escritores como el peruano César Moro y el centroamericano Rodrigo Rey Rosa? (Rivera Garza 2009)

Estos son solo unos pocos ejemplos latinoamericanos. Pero, y a diferencia de lo que ocurría antes, los narradores españoles más jóvenes también han salido del nido y han pasado largas temporadas fuera de España. El programa universitario Erasmus, las becas artísticas, doctorales o posdoctorales, la necesidad de renovar aires y culturas, y diversos motivos laborales han empujado a un enorme número de autores nacidos en España a ensanchar su geografía vital y literaria por América, Europa y Asia (véase la confesión de Antonio Orejudo al respecto: "Yo creo que para escribir una novela sobre tu cultura, sobre tu país, es muy útil hacerlo lejos. Nunca lo habría hecho si no me hubiera ido a Estados Unidos, si no hubiera vivido las mil experiencias tan diferentes a lo que entonces era mi país", 2011: 23), y se niegan a esclavizar sus narraciones a un lugar con- 
creto ${ }^{4}$. Por supuesto, este es un fenómeno global. Un ejemplo extremo podría ser el narrador Ilija Trojanow. Nacido en Bulgaria en 1965, fue criado después en alemán en Kenia y Alemania. En 1999 se fue a vivir cuatro años a Bombay, y luego pasó otros tres en Ciudad del Cabo antes de regresar a la ciudad alemana de Mainz en 2007. Javier Montes (2010), en un artículo de prensa sobre este tema, apunta nombres similares con similares peripecias biográficas: Marie Ndiaye, Miguel Syjuco, David Mitchell, Wells Tower o Aleksandar Hemon. Me atrevo a decir que este tipo de escritor, antaño limitado a entornos diplomáticos ${ }^{5}$, será cada vez más frecuente en los próximos decenios, a consecuencia de la globalización económica.

\section{INFORMACIÓN Y ESCRITURA}

Techos que a mí me cobijen cielos serán los mejores.

Manuel Altolaguirre

Al desplazamiento físico de todos estos autores en castellano hay que unir el informacional. Recuerdo una frase de Elías Canetti en Hampstead que me dio mucho que pensar en su momento, donde decía haber aprendido más sobre pulgas en una sola noche de lectura que en toda una vida de sesenta y cuatro años. En efecto, aunque el conocimiento inespecífico o cotidiano existe, el estudio deliberado es el que realmente trae el conocimiento. Y debido a que las nuevas tecnologías nos traen la información, y de nosotros solo depende convertir eliotianamente una parte de información en conocimiento, nos encontramos que los desplazamientos informacionales han contribuido a diluir las barreras entre los escritores hispánicos. Pensemos un ejemplo: un ecuatoriano aficionado al vino que hubiera dedicado una mañana a leer en Wikipedia sobre el modo de producción de los tintos de Rioja y la historia de esa región, que hubiese visto fotos de la zona en Google Imágenes, que buscase la ubicación exacta de las bodegas con el Google Earth y viese en Youtube vídeos turísticos o personales grabados en la zona, sabría sobre la Comunidad Autónoma de La Rioja más que la inmensa mayoría de los españoles (no riojanos, se entiende). Pensemos en la

\footnotetext{
4 Véase el caso del narrador gallego Juan Tallón, que en una novela hace decir a uno de sus personajes: "No entiendo este minufundismo [...] según el cual un escritor gallego tiene que dialogar antes que nada con escritores gallegos [...] ¿nuestros autores deberían situar el espacio narrativo de sus novelas en Galicia?" (2013: 105).

5 Un ejemplo canónico podría ser Nikko (1910), el singular libro "japonés" de Efrén Rebolledo, carente según Sarah S. Pollack de casi todas las lacras de la mirada extranjera sobre el país en que se vive. Rebolledo dominaba el japonés, criticaba el exotismo de algunas visiones como las de Pierre Loti, argumentaba que no pueden compararse ciertos elementos occidentales con los orientales y, en general, tenía una distancia cosmopolita y compleja sobre lo descrito, por no hablar de del "efectivo olvido en el que mantiene a la inmediata realidad mexicana" (Pollack 2011: 410). Como apunta la autora, "Leído de esta manera, Nikko irrumpe en las letras nacionales como un precedente radical de toda una genealogía de subjetividades alternativas en las siguientes décadas, desde la obra de los ateneístas (en particular Alfonso Reyes y José Vasconcelos) hasta la más reciente experiencia excéntrica del narrador y traductor Sergio Pitol" (2011: 408).
} 
revolución que supone esta disponibilidad inmediata de una vasta información para los efectos literarios. Un peruano que en 1980 encontraba en una novela española giros lingüísticos que no entendía, o referencias a regiones españolas desconocidas para él, se quedaba en blanco y seguramente se preguntaría si estaba perdiendo alguna clave importante de la historia. Del mismo modo, tampoco en 1980 se entendían en España algunas jergas de los jóvenes violentos de Los jefes de Vargas Llosa, o algunas localizaciones de Bryce Echenique, por no hablar de algunos términos incas recogidos por José María Arguedas o voces náhuatl citadas en La región más transparente de Carlos Fuentes. Hoy en día esos lectores tienen cerca un ordenador donde despejarán sus dudas de inmediato con la página del Diccionario Panhispánico de la Real Academia, en el que aparece lo que una misma palabra significa en Perú, en Argentina, en el Salvador, en España o en Estados Unidos. Gracias a Google el lector español sabrá qué cosa sea la yuca, y el peruano entenderá por fin que en España no cogen tanto como dicen en sus novelas, sino que en realidad solo agarran o jalan las cosas. Creo que es significativo, por exagerado, este párrafo de Nocilla Lab (2009), de Agustín Fernández Mallo: "no entiendo cómo alguien necesita desplazarse, usar los sentidos, viajar, para sentir algo, lo encuentro básico, primitivo, como un estadio primario de la evolución, hay otras formas más civilizadas de viajar sin salir de casa, por eso a mí con la tele, los libros, el computador y las pelis, ya me llega" (2009: 63). Otro ejemplo extremo sería el de la novela El exilio según Nicolás (2004), del uruguayo Gabriel Peveroni, donde el protagonista, "fingiendo ante todos ellos haber migrado a Miami [...] en realidad se encierra en su apartamento de Bulevar Artigas delante de su computadora" (2008: 48), como sintetiza Jesús Montoya. Si bien estos desplazamientos puramente virtuales y pueden ocasionar errores, desde luego suponen una voluntad comunicativa intercultural indudable. "Aunque el flujo desigual de materiales culturales a través de las fronteras nacionales produce con frecuencia una comprensión distorsionada de las diferencias nacionales", escribe Henry Jenkins, "también representa un primer paso significativo hacia la conciencia global" (2009: 73).

Toda esta red de deslocalizaciones, físicas e informativas, formadas a través de los viajes y de las navegaciones cibernáuticas, se convierte al final en una red de influencias literarias. Todos esos viajes no solo invitan a sumergirse en la cultura a la que se llega, sino que hacen mirar de distinta forma la cultura propia. Incluso cuando uno vuelve al país natal, ya no es el mismo. La narradora española Lolita Bosch ha vivido en México gran parte de su vida, y aunque reside ahora en Barcelona elabora antologías como Hecho en México, publicada por Mondadori en 2007, y sigue en contacto de forma activa con la realidad sociocultural mexicana. Jorge Carrión y Gabi Martínez han establecido sus obras sobre el concepto de metaviaje, el primero, y sobre la crónica de viajes el segundo, sumándose a un vasto número de escritores viajeros y escritores de crónicas hispanoamericanos antologados por el primero en Mejor que ficción (2012). El propio Carrión, en La brújula, escribía: "ha llegado la hora de ser coherentes con la idea de que ha caducado la división nacional de la literatura" (2006: 12). En efecto, no solo ha caducado sino que para estos autores comienza a parecer algo sospechosa. 


\section{LA REVOLUCIÓN DIGITAL}

Otro de los elementos clave en la progresiva dilución de la identidad nacional como eje cardinal en las narraciones es la aparición de Internet, más allá de los aspectos informativos. Como ya hemos abordado la revolución espacial de Internet en otro lugar nos limitaremos a recordar ahora que el ciberespacio ha generado un nuevo entorno (Tercer Entorno, lo denominaba Javier Echeverría en 1999), cuyas leyes no son parejas a las de las geografías tradicionales. Como consecuencia, según ha escrito la pensadora Rosa María Rodríguez Magda, en la red "no hay comportamiento observable, sino verbalización, retórica del hipertexto, orden metafórico, ficción. No hay nombre, sino seudónimo. La dirección (no física) como identidad, frente al alma, el lugar del no lugar. Y correlativamente a ello un proceso de desubicación social" (2010: 35$)^{6}$. La identidad nacional del internauta no es un valor en Internet, sino el lugar donde está en cada momento, debido a la difusión masiva de las tecnologías geoespaciales. Y el lugar de residencia o estancia puntual no tiene por qué coincidir con el de origen. Del mismo modo que el internauta, el escritor de nuestros días se adapta al sitio en el que está, y desde él irradia su actividad de escritura. Así lo ha explicitado Gustavo Valle en un artículo titulado "El país del escritor": "Yo creo haber aprendido a identificar, con enorme lentitud y esfuerzo, cuál es ese país. Y sin ánimo de dar lecciones creo que el país del escritor es simplemente el lugar donde escribe. El albergue, así sea accidental o provisorio, donde realiza su actividad" (2012: 56). En su novela Arena negra, a medias europea y a medias latinoamericana, Juan Carlos Méndez hace pensar a su protagonista: "No hay manera de que los sitios eviten que al moverte te lleves a ti misma en ti" (2013: 12).

La adaptación al medio es esencial al ciudadano nómada de nuestros días, cada vez más acostumbrado a cambiar de domicilio e incluso de país para encontrar trabajo. Ese ciudadano encuentra en lo digital un espacio de conversación y de recepción informativa no sujeto a aduanas ni control de inmigración, en el que puede campar a sus anchas, liberado de las molestias del desplazamiento. Su identidad (tanto la nacional como la subjetiva) se diluyen en la experiencia de la navegación, y puede reconstruirse y crear avatares a voluntad en el ciberespacio. Virgilio Tortosa ha explicado cómo las nuestras son "sociedades que se han ido progresivamente estructurando en el tira y afloja de la conflictiva relación red/sujeto, un mundo erigido en la tensión permanente entre la globalidad y la identidad más concretizadora" (2008: 259). Como explicábamos en otra parte, la mayoría de esa construcción es textual, se efectúa mediante una escritura personalizada (y "personalizante", performativa de lo subjetivo), de modo que el escritor está naturalmente adaptado al proceso de adaptación, y es permeable a la permeabilidad.

\footnotetext{
${ }^{6}$ Aunque el concepto de no-lugar ha sufrido diversas críticas, es obvio que ha tenido una clara difusión; de ahí que autores como Cabo Aseguinolaza comenten que tanto los autores del "Crack", como los de "McOndo" como algunos españoles propugnen "una literatura desligada de los cronotopos más estereotipados, en cierto modo sensible a los no lugares de la globalización" (2013: 448).
} 


\title{
7. LA VIRTUALIZACIÓN DE LA LITERATURA
}

Si profundizamos en estas experiencias, nos damos cuenta de que el escritor tiene la impresión de que puede remodelar, "formatear" su experiencia y su identidad gracias a las tecnologías. Lo real, o, mejor dicho, la idea de lo real, se diluye, se difumina y sus contornos se tornan borrosos. Las fronteras entre realidad y ficción son lábiles y estólidas desde siempre, pero en nuestros días esa es otra división que la tecnología digital hace desaparecer como por ensalmo. Josefina Ludmer (2007) ha establecido sobre esta grieta uno de los puntales de su hipótesis de lectura antes citada: "las literaturas posautónomas [...] se fundarían en dos [...] postulados sobre el mundo de hoy. El primero es que todo lo cultural [y literario] es económico y todo lo económico es cultural [y literario]. Y el segundo postulado de esas escrituras sería que la realidad [si se la piensa desde los medios, que la constituirían constantemente] es ficción y que la ficción es la realidad". A su juicio, estas literaturas "salen de la literatura y entran a "la realidad' y a lo cotidiano, a la realidad de lo cotidiano [y lo cotidiano es la TV y los medios, los blogs, el email, internet, etc.]. Fabrican presente con la realidad cotidiana y esa es una de sus políticas". Sin profundizar ahora en la validez de la propuesta de Ludmer, sí nos interesa el diagnóstico, puesto que la descripción es hacedera para entender ciertos cambios, algunos giros que se están produciendo en las literaturas actuales en castellano. Literaturas que se están virtualizando, que se están independizando cada vez más de la experiencia para acrisolarse en una reformulación que valida o da carta de naturaleza a lo literario con bastante independencia de su reflejo real.

Pongamos algún ejemplo. Comentando Diario de un joven escritor argentino (2005), de Juan Terranova, Luciana Irene Sastre apunta:

\begin{abstract}
... el breve relato del recuerdo de cómo fueron conocidos por el narrador los sucesos de diciembre de 2001 da entrada en el texto más a la reflexión sobre qué aportan los medios al escritor que a un posicionamiento respecto de los acontecimientos. El recuerdo es más un ejemplo de la afirmación del narrador acerca de que "el material que sale de la tele no es tan malo" (141) de tal modo que el objeto de interés es la reconstrucción mediática de lo ocurrido y no la experiencia de estar en el lugar del conflicto. (Sastre 2009)
\end{abstract}

Esta experiencia-simulacro, conformada por los medios de comunicación, tiene su paralelo en la mímesis simulacral que, a nuestro juicio, conforma un interesante sector de la literatura última en castellano, tanto ciberliteraria como tradicional, y que se caracteriza precisamente por devolver una imagen del mundo en los mismos términos mediáticos con que es recibida, tras ser procesada literariamente. Al presunto simulacro de lo real se contesta con otro simulacro, con un artefacto literario elaborado de forma textovisual, que demuestra hasta qué punto el escritor está impregnado de virtualidad y es capaz de responder a ella en los mismos términos.

Un proceso que se remonta a los últimos años del siglo pasado, cuando Internet ya era moneda de uso común en muchas partes del globo. En 2000, la 
venezolana Liduvina Carrera estaba investigando lo que denominó metaficción virtual en la narrativa hispanoamericana, poniendo como ejemplos obras de César Aira, Ricardo Piglia, Laura Esquivel o Jesús Díaz, entre otros. A su juicio,

... en lo que respecta a los textos de ficción, elaborados con las características de la metaficción virtual, surgen nuevos códigos para organizar el caos en que se ha visto sumergido el hombre y el personaje a un paso del tercer milenio, por esta razón la narrativa ficcional postmoderna crea una "realidad virtual alterna", donde todo espejismo genérico de la imagen sea aniquilada por el refinamiento técnico del holograma, de la realidad virtual o de la imagen tridimensional. (Carrera 2000: 50)

En nuestros días esta tendencia no solo ha continuado sino que ha multiplicado sus posibilidades y practicantes, quizá animados por cierto fatalismo o escepticismo ante la situación sociopolítica real (otra característica de la literatura posnacional, según ha señalado López Navia 2009: 233), que parece estimular el interés de la ficción hacia otros lugares.

\section{LA DIFUSA TERRITORIALIDAD DE LA NOVELA GLOCAL}

Para sentirnos en Inglaterra (donde ya estábamos) apuramos en rituales jarros de peltre cerveza tibia y negra.

J. L. Borges (1989: 393)

Todos los fenómenos tienen sus antecedentes. Julián Jiménez Heffernan ha encontrado los que corresponden a la literatura glocal en un relato de Jorge Luis Borges, "La memoria de Shakespeare", escrito en la última etapa de su vida. A su juicio, uno de los asuntos importantes de este relato es "la dispersión geográfica de sujetos internacionales", que sufren los tres protagonistas, Adam Clay, Daniel Thorpe y Herman Soergel. "Todo lector de Borges", dice Jiménez Heffernan,

es consciente de que esta situación de enajenación cultural es muy común en sus relatos, en gran medida porque muchos de ellos [...] se sitúan históricamente en el periodo europeo de entreguerras, un periodo caracterizado por este nomadismo planetario, militar, comercial y colonial, de ciudadanos altoeuropeos más o menos profesionalizados. En este escenario relativamente trasnacional tiene lugar la ulterior enajenación personal propiciada por la transferencia mnémica. La vulneración voluntaria de la inmunidad personal es más común, claro está, en individuos desasistidos de identidad nacional, comunitaria o cultural. (Jiménez Heffernan 2010: 299)

Autores como Cees Noteboom ("Recuerdo que le dije a mi madre, con la mochila lista: 'Me voy'. Nunca volví a casa"; 2013: 49), Gregor von Rezzori o el último José Saramago han hecho de ese desasimiento cultural concreto un hecho central de su obra, creando espacios narrativos neutros, susceptibles de ser 
reconocidos por cualquier lector con independencia de su origen; y el Austerlitz retratado en el libro homónimo de W. G. Sebald (2001) hace de la disolución identitaria entre lenguas y culturas europeas su único hogar posible. Merece la pena leer el poema de Izet Sarajlić, "Poetas errantes", que apunta otros casos:

Kundera y Cortázar han logrado la nacionalidad francesa, Brodski ha obtenido asilo en los Estados Unidos, / Nekrassov está en Alemania, / Gómez en España. / Gaston Salvatore, alemán en Chile, ha elegido domicilio / en Venecia. / Herbert Kuner está en Viena, Ion Milosz en Malmö, / Juan Octavio Prenz en Trieste. / Pentii Saarikoski nos ha contado recientemente en Struga / que desde hace tres años ya no vive en Finlandia. / Márquez pasa la mayor parte de su tiempo en el avión entre México y París. // Dos conclusiones se imponen solas: / o el mundo será bien pronto exclusivamente por inmigrantes / o tendrá que convertirse en la única patria universal de los hombres. (Sarajlić 2013: 78)

Estos antecedentes, que podríamos llamar cosmopolitas, se han trasformado (Seoane Pinilla 2010: 640). Como explica Pablo Raphael, "la globalización se impuso sobre el cosmopolitismo" (2011: 256). En efecto, el antiguo cosmopolitismo, algo elitista y siempre con matices culturales, se ha vuelto más pragmático y económico, por culpa de la globalización. Manuel Arranz ha apuntado que "hoy todo es global [...]. Hasta el término local es global. Desde hace décadas recorren el mundo flujos de dinero, información, imágenes, sentimientos, y, por supuesto, literatura, que han terminado por disolver las identidades más conspicuas. Y la literatura era tal vez el mejor reflejo de esas identidades" (2012: 166). Por ese motivo, en nuestros días, el nomadismo ya no es fatalmente europeo, como se reflejaba en el relato borgiano, sino universal. Por eso, es normal que los caracteres esenciales del subgénero estén claramente representados en una novela que no es europea -ni estadounidense-: Generation A (2009), del canadiense Douglas Coupland. Julien, uno de sus personajes, dice sobre sí mismo:

Una mujer me preguntó dónde trabajaban mis padres. Les dije que mi madre trabajaba para una empresa de generadores llamada Asea Brown Boveri y que mi padre trabajaba en la sección de software contable - de cadena vertical- del CERN.

- ¿Tienes hermanos o hermanas?

-Mi hermano trabaja en marketing en Kellog's. Mi hermana trabaja en Nokia, en Helsinki. ¿No os parece que mi familia está implicada en la globalización? Me han enviado a intercambios de inglés desde el parvulario. (Coupland 2011: 57)

Esta consciencia general de los procesos nomádicos a que conduce la globalización económica se advierte cada vez más claramente en la narrativa última, deuda no solo de ese espejo sociológico sino del propio natural viajero y transfronterizo de sus practicantes. Gustavo Guerrero plantea una interesante distinción entre las antiguas literaturas extraterritoriales y las desterritorializadas:

Lo interesante, sin embargo, es comprobar cómo se combinan en el discurso de Palou la vieja crítica cosmopolita del nacionalismo literario y la nueva que 
denuncia la reificación de las identidades y ataca la excluyente singularidad de nuestras culturas nacionales. Hay un tenue matiz entre ambas, pero que no se puede dejar de tener en cuenta a la hora de entender la diferencia entre la práctica de la ficción extraterritorial que se halla en escritores como Borges o, más atrás en el tiempo, Darío, y el tipo de ficción desterritorializada que traduce una intencionalidad distinta entre los jóvenes autores de las últimas décadas. (Guerrero 2012: 78)

Como ejemplos de este último sendero narrativo cita Guerrero a los otros miembros del crack mexicano, así como a Fresán, Lemebel, Thays, Ponte, Iwasaki o Bellatin. Un ejemplo significativo de esta ficción desterritorializada sería Breve teoría del viaje y el desierto (2011), del español Cristian Crusat, conjunto de seis relatos donde cada uno de ellos está ambientado en un país diferente, con ambientaciones creíbles en todos los casos. A juicio de J. M. Pozuelo Yvancos, la narrativa española última "se ha hecho muy plural y estéticamente compleja, quizá debido a la saludable internacionalización de las apuestas que han abordado los escritores que actualmente importan en España. Por así decirlo, la novela española se ha ido haciendo progresivamente menos castiza" (2011: 92). En correspondencia lógica con ello, otra de las notas de la novela glocal es, como es lógico, la ambientación de los libros en todo tipo de lugares, quedando el país de origen solo como centro de operaciones desde el que se irradia la acción o incluso como simple escenario secundario o inexistente. En un artículo significativamente titulado "Nadie escribe sobre España", Andrés Ibáñez recuenta de este modo:
Y así vemos, por ejemplo, que Pablo d'Ors escribe sobre Alemania, que Andrés Ibáñez escribe sobre Nueva York o sobre China, que David Torres escribe sobre los griegos, que Pilar Adón escribe sobre Tánger, que Blanca Riestra escribe sobre Albuquerque, que Eduardo Lago escribe sobre Brooklyn. [...] Menéndez Salmón escribe sobre la II Guerra Mundial, Ismael Grasa sobre Los Ángeles, Mario Cuenca sobre la guerra de Corea. Esther García Llovet, en su fascinan- te Submáquina [...] escribe sobre México, sobre el submundo de una Ciudad Juárez transfigurada. (Ibáñez 2010: 8)

No solo García Llovet; Ciudad Juárez ha sido también utilizada como espacio narrativo por el chileno Roberto Bolaño, el boliviano Edmundo Paz Soldán y por el poeta español José Luis Gómez Toré. En el mismo sentido que Ibáñez se pronuncia José María Merino, al reseñar una antología de relatos: "también en la perspectiva del realismo hay otros cuentos en los que llama sobre todo la atención del lector es lo que pudiéramos denominar, con neologismo proveniente del mundo industrial, la 'deslocalización' de los relatos, la falta de referente conocido o familiar, pues en bastantes casos apenas parecen tener nada que ver ni con España ni con sus gentes". Y continúa:

En el caso de la antología de Valls-Pellicer, Fernando Clemot presenta una historia de evocaciones desde la mala conciencia en una comarca italiana y mediante personajes exclusivamente italianos; Pilar Adón nos ofrece un lugar indeterminado [...]; Óscar Esquivias nos habla del miedo a vivir, también en un 


\begin{abstract}
escenario italiano y con personajes exclusivamente italianos; Jon Bilbao, para describir la crueldad de un ajuste de cuentas, nos presenta a un conjunto de jóvenes en una excursión por ciertos parajes norteamericanos -como el Yosemite Valley- sin que haya una presencia española determinada; Miguel Serrano nos cuenta cómo el dolor impide la comunicación en la evocación de ciertas fiestas comunales en algún "no lugar", donde hasta los personajes han perdido sus nombres; por último, Elvira Navarro elige también un lugar indeterminado para hablarnos de la soledad y de la difícil comunicación. Esa tendencia "deslocalizadora", que ya se apuntaba en la recopilación Pequeñas resistencias. Antología del nuevo cuento español, preparada por Andrés Neuman (Madrid, Páginas de Espuma, 2002) y que no tiene la coartada del subgénero -terror, fantasía, etc.indica una peculiar característica de bastantes de nuestros más jóvenes cuentistas contemporáneos. (Merino 2010)
\end{abstract}

Otra posibilidad diferente de superación de la idea tradicional de nación es situar la acción en territorios innominados, intercambiables, en los que apenas son reconocibles los rasgos de lo urbano (o de lo rural, como en Intemperie de Jesús Carrasco), por lo común habitados por personajes también sin nombre y también intercambiables, dotados de subjetividad epidérmica (pensemos en Gran Vidrio de Mario Bellatin, en Labia de Eloy Tizón, en Click de Javier Moreno o en Sol artificial, de J. P. Zooey). Un caso extremo sería el género de la distopía postapocalíptica, al modo de la brutal Plop (2002) de Rafael Pinedo o de la desaforada Rockabilly de Wilson, donde el espacio arrasado no responde no solo a ninguna pauta nacional, sino ni siquiera a esquemas civilizatorios.

La última de las características esenciales de esta geolocalización, que parece regida por el Google Earth, es que las diversas geografías presentan a diferentes personajes, muchas veces de idiomas e incluso origen étnico distinto, que quedan enlazados o conectados gracias a la tecnología mágica de la ficción, o a la ficción mágica de la tecnología. Así, Providence (2009), de Juan Francisco Ferré (que vive a caballo entre España y Estados Unidos), se localiza en lugares tan distintos como Cannes, España, Providence o Marrakech, con apariciones de personajes rusos, que mantienen su propia personalidad de origen mientras hablan en inglés o francés. El hacedor (de Borges), Remake (2011) de Agustín Fernández Mallo realiza "viajes" virtuales gracias a Google Street View a islas mediterráneas o a New Jersey para revisitar escenarios de películas o actuaciones artísticas. Otros ejemplos serían Crónica de viaje (2009) de Jorge Carrión o los 13 viajes in vitro (2008), resultado de un desplazamiento puramente virtual, de Mercedes Cebrián.

\title{
9. El español y el PANESPAÑol
}

No soy poseedor de una estética. El tiempo me ha enseñado algunas astucias: [...] eludir hispanismos, argentinismos, arcaísmos y neologismos.

Amén de las geografías y las referencias culturales, también se ha apuntado cómo el idioma con que se escriben las ficciones en el mundo hispánico está 
cambiando, y varias tendencias se están produciendo al mismo tiempo. A juicio de Ramón Acín,

en la obra de algunos escritores jóvenes ya se puede observar la presencia de una escritura creativa que no solo se apoya en lo lingüístico. Una escritura que mezcla idiomas -lógico en nuestro mundo globalizado- en un mismo discurso frente al uso tradicional de idioma único -el propio de la nación del escritor-. Una escritura creativa donde el lenguaje no solo es literario, sino una mixtura procedente de varios frentes, como el musical, digital, matemático, cinematográfico, fotográfico, publicitario, plástico, etc. -resultado, también lógico, dadas las nuevas formas de acceso a la realidad y del procesamiento de la realidad-. (Acín 2011: 15-16)

Las ficciones más convencionales siguen manteniendo el idioma de sus antecesoras, tanto en Hispanoamérica como en España. Aquellas que acusan estos procesos de desterritorialización que describimos, en cambio, están escritas en un español alterado, no convencional y singular para cada autor. Como es difícil encontrar leyes universales, mejor examinemos algún ejemplo concreto.

El escritor mexicano José Ramón Ortiz reproduce en los cuentos de Los días con Mona (2011) varias inflexiones del castellano global, y también algunas de las geoestrategias que hemos visto. Su relato "Drosophila Melanogaster" está ambientado en Madrid, aunque se oyen ecos uruguayos, españoles y mexicanos en los diálogos. En "Los días con Mona", un extraño relato de zombies narrado con sombrío realismo, parece deducirse que Mona es estadounidense aunque los dos personajes hablan en español con algún localismo mexicano, como "cogía" (2011: 21) -si bien la narración podría ser una traducción ficticia de una conversación en lengua inglesa-. El relato "Vietnam" aborda la relación de amistad entre Larry Casanova, un ex marine, y Buck, el narrador, que hablan en inglés (2012: 38, 43). "Las excavadoras" presenta a un narrador con una peripecia quizá en parte autoficcional que viaja hasta Miranda, un país imaginario situado en África; la referencia de Miranda está tomada de El discreto encanto de la burguesía, de Buñuel (Ortiz 2011: 64), aunque también el colombiano Antonio Ungar ha utilizado a Miranda, si bien localizándola en América, en su novela Tres ataúdes blancos (2010). Estos relatos "globales" componen la primera parte del libro de Ortiz, "Los días con Mona". Frente a su diversidad geográfica, tonal, de narratarios y de códigos lingüísticos, los tres relatos agrupados en la segunda parte, titulada "Cuestión de negocios", guardan una conformación más homogénea en todos los aspectos. Los tres cuentos están ambientados en el norte de México, el lenguaje se vuelve muy localista y los temas son comunes: la violencia y el narco. Aunque en los demás relatos aparece igualmente la violencia de un modo u otro, en estos cuentos liminares cobra un notable -casi exclusivo-protagonismo. Parece como si para el autor los problemas de su país requiriesen de un tratamiento lingüístico y estético especial, pero lo importante es que Ortiz amolda el idioma español a las circunstancias geográficas de cada relato, adaptándolo a sus concretas necesidades narrativas.

Lina Meruane ha expresado explícitamente estas variedades lingüísticas en Sangre en el ojo (2012), novela en la que recrea su vida sentimental con un 
profesor español. En cierto momento la trama representa el instante en que este último hace la compra en un supermercado de Santiago de Chile:

Por los pasillos del supermercado Ignacio se dedicó a cazar sustantivos en las latas de comida, damascos en vez de albaricoques, arvejas en vez de guisantes, porotos y no judías, y entonces yo me paré ante un mostrador y pasando suavemente los dedos como lectores láser por las superficies le dije acá hay tarros en vez de latas, de choclo en vez de maíz. (Meruane 2012: 109)

Junto a estos fenómenos de convivencia de distintos modos de expresión sin salir del castellano, comienza a detectarse en la narrativa hispánica otro diferente, la aparición de lo que podríamos llamar el panespañol. Este dialecto literario consistiría en una especie de castellano estándar mediante el que los escritores van moderando los modismos, eliminando las expresiones localistas, para ser más y mejor entendidos, cualquiera que sea el lugar de Hispanoamérica donde sean leídos? ${ }^{7}$ La profesora Adélaïde de Chatellus ha declarado en alguna ocasión que al traducir al francés la narrativa de Andrés Neuman y Méndez Guédez fue consciente de que había más particularidades idiomáticas en sus primeras novelas que en las últimas. Frente al color local de escritores como Carlos Velázquez, otros autores como Neuman, Villoro, Zambra, Volpi o Padilla, por ejemplo, escriben desde estas coordenadas. Su lengua de redacción es posnacional, está situada más allá de las singularidades idiomáticas o culturales concretas de un solo país, peculiaridades que cuando aparecen de forma puntual en los libros están ilustradas, explicadas para lectores no originarios. Rafael Lemus, reseñando Óscar y las mujeres (2013) de Santiago Roncagliolo, apunta alguno de estos elementos:

De hecho, no es aventurado afirmar que varias de las estrategias narrativas puestas en práctica aquí son, justamente, las estrategias hegemónicas de una cierta novela panhispánica promedio: narrador omnisciente y en tercera persona; español estándar, cuidadosamente expurgado de vocablos y modos locales que podrían obstruir su circulación en diferentes mercados nacionales; trama intimista, más o menos sentimental, empeñada en no atender el contexto en que se sitúa; tono levemente irónico que, en vez de demoler los estereotipos disponibles, los emplea un instante después de haberse burlado tímidamente de ellos; nulo compromiso político. (Lemus 2013: 72)

Como es lógico, hay razones de mercado junto a las literarias que explican estos procesos; pero existe también a nuestro juicio la conciencia de estar más

\footnotetext{
7 Sobre Patricio Pron, escribe Marcos Seifert (2011): "Otra de sus acometidas apunta hacia 'el lado de acá': el uso de un español despojado de toda marca rioplatense. De alguna manera, su ejercicio de apropiación de 'otra lengua', si bien nos recuerda a los desplazamientos de Rodolfo Wilcock y Héctor Bianciotti, es más sutil, pero no por eso deja de ser provocador. Su lengua, que nos remite al español plano autotraducido del Puig de Maldición eterna a quien lea estas páginas, es una lengua robada del español neutral de las traducciones, una lengua apátrida. Pron cuestiona las relaciones entre lengua y propiedad y busca eliminar toda naturalidad y familiaridad que engendra la cercanía".
} 
allá de las fronteras. Es normal que Villoro o Neuman intenten ser entendidos universalmente, porque sus públicos son universales, ya no son exclusivamente el mexicano o el español, como cuando empezaron. Ambos han vivido mucho tiempo fuera de sus países de nacimiento y escriben para cualquier lector hispano. Señala Daniel Link la forma en que algunos escritores latinoamericanos, como Aira o Bellatin "han decidido vivir en la intemperie del mundo [...] en la errancia de una escritura que se quiere excéntrica y cada vez menos reconocible como idioma nacional, como novela, o incluso como estilo y hasta como literatura", añadiendo que, en el caso de Bellatin, "no hay patria, no hay lenguaje nacional, ni límites ni distancias" (2008: 62-63). La lengua, la cultura, son en nuestros días algo mucho más importante que la correspondencia con un territorio concreto. Los narradores actuales en castellano se presentan como hiperterritoriales, posnacionales, deslocalizados, sin que ello implique que renuncien a su tradición propia, sino que suman otras a ella. No rechazan su idioma, pero aprenden otros. Con independencia del modo en que ellos se presenten a sí mismos, sus obras no son ya latinoamericanas, ni iberoamericanas, ni peninsulares, sino hispánicas ${ }^{8}$. Su cultura nativa aparece en sus novelas, pero también la de los lugares en que han vivido o sobre los que se han informado. Habrá quien cuestione este proceso, pero no tiene por qué ser perjudicial. El escritor glocal en español no escribe para su entorno, sino para un lector en castellano que puede o no ser el de su lugar de origen. Ya no se escribe para algunos, sino para todos. El escritor se ha vuelto portátil, como expresaba con acierto Manuel Vilas:

La portabilidad de la literatura y del escritor puede engendrar una excitante pérdida de identidad, en la medida en que el territorio global o el territorio pangea se basa en la renuncia a las identidades locales y nacionales. El proceso de pérdidas de identidades nacionales acaba de empezar, es sumamente reciente. Perder las identidades nos hará más libres. Estaremos mejor. Creo que el proceso de portabilidad es esencialmente una liberación. El siglo xIX generó unas camisas de fuerza ideológicas que aún están presentes. Y una de esas camisas fue la idea de las literaturas nacionales, idea que favoreció a las grandes identidades nacionales europeas. (Vilas 2009a) ${ }^{9}$

También, desde el otro lado del océano, Valeria Luiselli ha tendido puentes hacia el XIX para explicar las tensiones en que viven inmersos los escritores hispanos de hoy, y su derecho de elegir su identidad:

Los mitos fundacionales de América Latina fueron, en su mayoría, resultado de dos elementos en constante tensión: por un lado, de una mirada autorreflexiva $y$, por otro, de la mirada hacia un proyecto futuro de naciones independientes de Europa, distintas de ella, plenamente originales. Esa tensión, esa mirada es-

\footnotetext{
8 Un buen ejemplo sería el libro que une a poetas españoles y latinoamericanos para reflexionar sobre poesía en castellano, Poesía hispánica contemporánea, editado por Andrés Sánchez Robayna y Jordi Doce, y publicado por Círculo de Lectores en 2005.

${ }^{9}$ Vilas escribía sobre Nocilla Lab (2009a), de Fernández Mallo, en estos términos: "En 180 páginas Mallo construye el Aleph de este tiempo, de este 2009. Es una novela global. La pueden entender en Asia, en Dinamarca o en Nairobi. Está en consonancia con este momento de la historia".
} 
trábica, constituyó los textos literarios decimonónicos y de principios del siglo $x x$ que sirvieron de base para la construcción de las identidades nacionales de los entonces incipientes países latinoamericanos. ¿Pero ahora, en pleno siglo XXI, debemos seguir subrayando que nuestra identidad es tal o cual cosa? Es como si los argentinos jóvenes siguieran escribiendo sobre los gauchos. $\mathrm{O}$, mejor dicho, como si los críticos del cono sur siguieran buscando la identidad literaria nacional en la dicotomía ya rancia de la civilización y la barbarie. (Luiselli 2012)

Y, en el mismo sentido, la escritora Mercedes Cebrián decía en una poética que "un verbo útil es ampliar" (2009: 300), y numerosos autores y críticos reivindican un modo posnacional no ya de entender la escritura, sino de plantear el hispanismo y el estudio sobre estos textos, en la órbita del profesor peruano Julio Ortega y sus Congresos Transatlánticos. En ese sentido, los narradores españoles actuales más interesantes son posespañoles, o quizá mejor transespañoles, puesto que no han dejado de ser españoles, sino que están más allá de esa limitada definición, a la que no se ajustan sus libros glocales. Sus narraciones tienen lugar en Tokio (Olmos), Nueva York (Loriga, Andrés Ibáñez), Oxford (Javier Marías), México (Vila-Matas), Brasil (Pàmies), Providence (J. F. Ferré), Londres (Menéndez Salmón, Jon Bilbao), Chicago (J. M. de Prada), Pekín (Gabi Martínez, Miguel Espigado), Australia (Carrión), Marruecos (Lorenzo Silva, Fernando Marías), Los Ángeles (Germán Sierra), Alemania (Luis Manuel Ruiz, Menéndez Salmón, Fernando Aramburu), el océano Antártico (Sánchez Piñol), Albuquerque (Blanca Riestra), Europa (Mercedes Cebrián), inidentificables territorios estadounidenses (Cercas, Gutiérrez Solís, Pérez Azaustre, Trejo), irreconocibles lugares deslocalizados (Juan Bonilla, Ángel Zapata, Eloy Tizón), o el espacio exterior (Elia Barceló).

\title{
CONCLUSIONES
}

\author{
$Y$, finalmente: \\ dichoso aquel que tiene sus lugares de duración; \\ aunque esté para siempre desplazado en tierra ajena, \\ sin perspectivas de regreso a su entorno, \\ no será ya un exiliado de su patria.
}

Peter Handke, Poema a la duración

Como bien ha expresado Santos Sanz Villanueva, "la lógica dice que no puede ser igual el artefacto literario crecido en pleno asentamiento decimonónico de la burguesía que el adecuado a la sociedad de la información" (2011: 3). Sea posnacional o no, aunque seguramente lo es en gran medida, creemos que hay una novela glocal en castellano, caracterizada precisamente por su tensión identitaria entre el cosmopolitismo y las raíces, entre la diáspora (Belting 2003: 73) y la lealtad al lugar, entre la inquietud por la cultura global (que no globalizada) y el recuerdo de la cultura propia. Esta novela glocal, de la que hemos citado varios y muy diferentes ejemplos, presentaría una descripción característica ligada bien a una territorialidad difusa, bien a una multiterritorialidad (con 
un uso del español adaptado a cada caso); además, entre sus notas descriptivas podrían encontrarse asimismo el empleo de medios de comunicación de masas como modelo informativo básico de los personajes, la comunicación digital a través de Internet, y la cualidad móvil o nómada (sea física, informacional, o ambas) de sus personajes. Teniendo en cuenta que los posibles factores de aparición y desarrollo que hemos estudiado no parecen remitir, y que, por el contrario, parecen calificarlos como cualificados para la permanencia, es dable afirmar que la literatura posnacional y la novela glocal como género de la misma son líneas estéticas con un largo futuro por delante.

\section{OBRAS CITADAS}

Acín, Ramón (2011): "Incertidumbres de futuro, multitud de miradas e insatisfacción de plenitud". En: Sanz Villanueva, Santos (ed.): Nueva novela española, número especial de La página, n. ${ }^{\circ}$ 93-94, pp. 5-18.

Apablaza, Claudia (2010): Diario de las especies. Sevilla, Barataria.

Arranz, Manuel (2012): "La literatura entra al trapo". En: Fernando Aguiar, Alicia García Ruiz y Alberto J. Ribes (comps.): Entre líneas. Ensayos sobre literatura y sociedad. Madrid, CSIC, pp. 165-176.

Bellatin, Mario (2011): Disecado. Madrid, Sexto Piso.

Belting, Hans (2003): Art History after Modernism. Chicago, The University of Chicago Press. Borges, Jorge Luis (1989): Obras completas, tomo III. Buenos Aires, Emecé.

Borja, Jordi, y Castells, Manuel (1997): Local y global. La gestión de las ciudades en la era de la información. Madrid, Taurus.

Boullosa, Carmen (2012): "Más acá de la nación". En: Revista de Estudios Hispánicos, n. ${ }^{\circ} 46$, pp. $55-72$.

Cabo Aseguinolaza, Fernando (2013): Historia de la literatura española. 9. El lugar de la literatura española. Barcelona, Crítica.

Carrera, Liduvina (2000): La metaficción virtual. Hacia una estrategia posible en la narrativa finisecular latinoamericana del siglo xx. Tesis doctoral, Caracas, Universidad Católica Andrés Bello.

Carrión, Jorge (2006): La brújula. Córdoba, Berenice.

- (2009): Viaje contra espacio. Juan Goytisolo y W. G. Sebald. Madrid, Iberoamericana. (2010): Los muertos. Barcelona, Mondadori.

(2013): “¿Dolernos? Compromiso político y s. xxı". En: Quimera, n. ${ }^{\circ} 351$, pp. 24-28.

Castany Prado, Bernat (2007): Literatura posnacional. Murcia, Universidad de Murcia. (2012): "Literatura antipatriótica". En: Quimera, n. ${ }^{\circ} 348$, p. 17.

Cebrián, Mercedes (2009): "Cosas que quiero, que detesto, que sé (a modo de poética)". En: Quimera, n. ${ }^{\circ}$ 300, pp. 62-63.

Coupland, Douglas (2011): Generación A. Barcelona, El Aleph Editores.

Duque, Félix (2006): El cofre de la nada. Deriva del nihilismo en la modernidad. Madrid, Abada.

Echeverría, Javier (1999): Los señores del aire: Telépolis y el Tercer Entorno. Barcelona, Destino. 
Esteban, Ángel, y Montoya Juárez, Jesús (2008): “¿Desterritorializados o multiterritorializados? La narrativa hispanoamericana en el siglo xxı". En: Francisca Noguerol et al. (eds.): Literatura más allá de la nación. De lo centrípeto y lo centrífugo en la narrativa hispanoamericana del siglo XXI. Madrid, Iberoamericana, pp. 7-14.

Estefanía, Joaquín (1997): Contra el pensamiento único. Madrid, Taurus.

Fernández Mallo, Agustín (2009): Nocilla Lab. Madrid, Alfaguara.

Fontana, Josep (2011): Por el bien del imperio. Una historia del mundo desde 1945. Barcelona, Ediciones Pasado y Presente.

Franco, Jean (2008): "Narrativas de la globalización". En: Quimera, n. 300, pp. 19-22.

García Canclini, Néstor (2005): La globalización imaginada. Buenos Aires, Paidós.

García Rodríguez, Javier (2012): "Cultura del Post y sociedad Thermomix®: Géneros literarios y consumo". En: Revista de Alces xxI, n. ${ }^{\circ}$ 0, pp. 298-313.

González, Aníbal (2012): "Adiós a la nostalgia: la narrativa hispanoamericana después de la nación". En: Revista de Estudios Hispánicos, n. ${ }^{\circ} 46$, pp. 83-97.

Guerrero, Gustavo (2012): "Literatura, nación y globalización en Hispanoamérica: explorando el horizonte post-nacional". En: Revista de Estudios Hispánicos, n. ${ }^{\circ} 46$, pp. 73-81.

Halfon, Eduardo (2010): "El destierro guatemalteco". En: Cuadernos Hispanoamericanos, n. ${ }^{\circ}$ 727, pp. 23-26.

Handke, Peter (2009): Vivir sin poesía. Trad. Sandra Santana. Madrid, Bartleby.

lanes, Raúl (2006): "Hermenéutica colonial e historicismo transatlántico en la ficción del XIX hispanoamericano". En: Hispanic Review, n. ${ }^{\circ}$ 74, 4, pp. 379-396.

Ibáñez, Andrés: "Nadie escribe sobre España". En: $A B C$ de las Artes y las Letras. $A B C$, 18.12.2010, p. 18.

Jenkins, Henry (2009): Fans, blogueros y videojuegos. La cultura de la colaboración. Barcelona, Paidós.

Jiménez Heffernan, Julián (2010): "El cuerpo de la escritura. La novela como prótesis de identidad". En: Gabriel Aranzueque (ed.), Ontología de la distancia. Filosofías de la comunicación en la era telemática. Madrid, Abada, pp. 293-340.

Languetin, Pierre (1988): Introduction: Transformation of the Banking and Financial Environment. Mikdashi, Ed. International Banking.

Link, Daniel (2008): "La imaginación novomundana. En torno al problema identitario en el Nuevo Mundo". En: Quimera, n. ${ }^{\circ} 291$, pp. 62-63.

López Navia, Santiago Alfonso (2009): "Literatura posnacional". En: Monteagudo: Revista de literatura española, hispanoamericana y teoría de la literatura, n. ${ }^{\circ}$ 14, pp. 231-235.

Ludmer, Josefina (2007): "Literaturas postautónomas". En: Ciberletras: Revista de crítica literaria $y$ de cultura, n. ${ }^{\circ}$ 17. Disponible en <http://www.lehman.cuny.edu/ ciberletras/v17/ludmer.htm>. Última visita: 16.08.2013.

Luiselli, Valeria (2012): "Novedad de la narrativa mexicana ॥: Contra las tentaciones de la nueva crítica". En: Nexos. Disponible en <http://www.nexos.com.mx/?P=leerarticul o\&Article=2102557>. Última visita: 01.06.2013.

Mandolessi, Silvana (2011): “¿Es posnacional la literatura argentina contemporánea? Apuntes para un debate". En: Mitologías hoy, n. 1, pp. 60-79.

Méndez Guédez, Juan Carlos (2013): Arena negra. Madrid, Casa de Cartón. 
Menéndez, Ronaldo (2005): "Como la mala hierba". En: Ronaldo Menéndez, Ignacio Padilla y Enrique Del Risco (eds.): Pequeñas resistencias / 4. Antología del nuevo cuento norteamericano y caribeño. Madrid, Páginas de Espuma.

Merino, José María (2010): "De nuevos cuentistas españoles". En: Revista de Libros, n. ${ }^{\circ} 165$. Disponible en <http://www.revistadelibros.com/articulos/de-nuevos-cuentistasespanoles>. Última visita: 16.08.2013.

Meruane, Lina (2012): Sangre en el ojo. Madrid, Caballo de Troya.

Molinuevo, José Luis (2004): Humanismo y nuevas tecnologías. Madrid, Alianza.

Montes, Javier (2010): "Raíces del futuro literario". En: Babelia. El País, 9 de julio, p. 12.

Montoya Juárez, Jesús (2008): "La Suisse n'existe pas: una reescritura poshumana y transnacional de la identidad uruguaya". En: Francisca Noguerol et al. (eds.): Literatura más allá de la nación. De lo centrípeto y lo centrífugo en la narrativa hispanoamericana del siglo Xxı. Madrid, Iberoamericana, pp. 45-60.

Mora, Vicente Luis (2006): Pangea. Internet, blogs y comunicación en un mundo nuevo. Sevilla, Fundación José Manuel Lara.

Navajas, Gonzalo (2012): "La literatura posnacional del siglo xxı". En: Revista de Alces XXI, n. ${ }^{\circ}$ 0, pp. 154-179.

Noguerol, Francisca (2008): "Narrar sin fronteras". En: Jesús Montoya Juárez y Ángel Esteban (eds.): Entre lo local y lo global. La narrativa latinoamericana en el cambio de siglo (1990-2006). Madrid, Iberoamericana, pp. 19-34.

Noteboom, Cees (2013): Entrevista en Letras Libres, n. ${ }^{\circ}$ 137, pp. 48-51.

Nuez, Iván de la (2010): El mapa de la sal. Cáceres, Periférica.

Ortiz, Joserra (2011): Los días con Mona. México D.F., Fondo Editorial Tierra Adentro, CONACULTA.

Pollack, Sarah S. (2011): "'El supremo bien de la libertad': Efrén Rebolledo, Nikko, y la articulación de una identidad postnacional". En: Romance Notes, vol. 51, n. 3 , pp. 405-414.

Pozuelo Yvancos, José Ma (2011): "Nueva narrativa española". En: Santos Sanz Villanueva (ed.): Nueva novela española, número especial de La página, n. ${ }^{\circ}$ 93-94, pp. 91-112.

Quesada Gómez, Catalina (2011): "Una cultura postnazionale". En: Nuova Prosa, n. ${ }^{\circ}$ 56-57, pp. 33-50.

Raphael, Pablo (2011): La Fábrica del Lenguaje, S.A. Barcelona, Anagrama.

Rivera Garza, Cristina (2009): "Unidades de dispersión". En: Milenio, 9 de junio. Disponible en <http://monterrey.milenio.com/cdb/doc/impreso/8588771>. Última visita: 16.08.2013.

Rodríguez Ibáñez, Margarita (2012): Cómo la Red ha cambiado el arte. Gijón, Trea.

Rodríguez Magda, María Rosa (2010): Razón digital y vacío. Valencia, Diputació de Valencia, Institució Alfons el Magnànim.

Romero López, Dolores (2008): "La literatura española en el siglo xxl: hacia la nueva creación digital". En: Dolores Romero López y Amelia Sanz Cabrerizo (eds.): Literaturas del texto al hipermedia. Barcelona, Anthropos, pp. 213-227.

Sanz Villanueva, Santos (2011): "Presente y futuro de la novela española". En: Santos Sanz Villanueva (ed.): Nueva novela española, número especial de La página, n. ${ }^{\circ}$ 93-94, p. 3. 
Sarajlić, Izet (2013): Sarajevo. Granada, Valparaíso Ediciones.

Sastre, Luciana Irene (2009): "El presente en consonancia". En: vı Encuentro Interdisciplinario de las Ciencias Sociales y Humanas. Disponible en <http://publicaciones.ffyh.unc. edu.ar/index.php/6encuentro/article/view/155>. Última visita: 01.06.2013.

Saum-Pascual, Alexandra (2012): Mutatis mutandis. Literatura española del nuevo siglo XxI (Dissertation). Riverside, University of California.

Seifert, M. (2011): "Vivir afuera". En: Bocadesapo, 30 de diciembre. Disponible en <http:// reseniasbds.blogspot.com/2011/12/vivir-afuera-por-marcos-seifert_30.html>. Última visita: 01.06.2013.

Seoane Pinilla, Julio (2010): "En torno a la actualidad de Cosmópolis". En: Isegoría, n. ${ }^{\circ} 43$, pp. 631-641.

Tallón, Juan (2013): El váter de Onetti. Barcelona, Edhasa.

Terceiro, José B., y Matías, Gustavo (2002): Digitalismo. Madrid, Taurus.

Tortosa, Virgilio (2008): "Sujetos mutantes: nuevas identidades en la cultura". En: Dolores Romero López y Amelia Sanz Cabrerizo (eds.): Literaturas del texto al hipermedia. Barcelona, Anthropos, pp. 257-272.

Valle, Gustavo (2012): "El país del escritor". En: Cuadernos Hispanoamericanos, n. ${ }^{\circ}$ 750, pp. 47-56.

Vilas, Manuel (2009a): "Decálogo sobre los territorios portátiles del escritor", <http://www. dvdediciones.com/vacaciones_vilas.html>. Última visita: 01.06.2013.

(2009b): "Nocilla Lab de Agustín Fernández Mallo", <http://manuelvilas.blogspot.com/2009/10/nocilla-lab-de-agustin-fernandez-mallo.html>. Última visita: 01.06.2013.

Volpi, Jorge (2008): Mentiras contagiosas. Madrid, Páginas de Espuma. 